\title{
Immuno-Efficacy of Multi-Epitope Chimeric Peptides Against Foot and Mouth Disease Virus: Potential Vaccine Candidates for Newly Emerged Serotype $O$ and $A$
}

\author{
Salma Akter ${ }^{1,2}$, M. Shaminur Rahman ${ }^{1}$, M. Rafiul Islam ${ }^{1}$, Masuda Akther ${ }^{1,}$ Mafruha Marjia ${ }^{1}$, \\ Md. Mizanur Rahman ${ }^{1}$, Munawar Sultana ${ }^{1 *}$ and M Anwar Hossain ${ }^{1,3 *}$ \\ 1 Department of Microbiology, University of Dhaka, Dhaka-1000, Bangladesh. \\ 2 Department of Microbiology, Jahangirnagar University, Savar, Dhaka-1342, Bangladesh. \\ 3 Present Address: Vice-Chancellor, Jashore University of Science and Technology, Jashore-7405, Bangladesh. \\ Correspondence: \\ - M Anwar Hossain, Professor, Dept. of Microbiology, University of Dhaka; \\ Email: hossaina@du.ac.bd ; and, \\ - Dr. Munawar Sultana, Associate Professor, Dept. of Microbiology, University of Dhaka; Email: \\ munawar@du.ac.bd
}

\begin{abstract}
Artificially designed, chimeric peptide-based recombinant vaccines are novel approaches to combat the phylogenetically diverse Foot and Mouth Disease (FMD) Virus (FMDV) strains. Among seven distinct serotypes, only serotype $\mathrm{O}$ and $\mathrm{A}$ are dominantly circulating in Bangladesh and neighbouring countries of Asia, where transboundary transmission, recurrent outbreaks and emergence of novel lineages FMDV are highly prevalent. The objective of this study was to develop multi-epitope recombinant peptides, procuring immunogenicity against circulating diverse subtypes of FMDV serotype $\mathrm{O}$ and A. Two chimeric peptides, named B1 (41.0 kDa) and B3 $(39.3 \mathrm{kDa})$, have been designed to incorporate potential B-cell and T-cell epitopes selected from multiple FMDV strains, including previously reported and newly emerged sub-lineages. After expression, characterization and immunization of guineapigs with considerable antigen load of B1 and B3 followed by the serological assays revealed the significant protective immunogenicity, developed from the higher $(100 \mu \mathrm{g})$ doses of both antigens, against most of the currently prevalent serotype $\mathrm{O}$ and A strains of FMDV. The efficient expression, antigenic stability, and multivalent immunogenic potency of the chimeric peptides strongly indicate their credibility as novel vaccine candidates for FMDV serotypes $\mathrm{O}$ and A circulating in Bangladesh and surrounding territories.
\end{abstract}


Keywords: Artificially designed, chimeric peptides, expression, FMDV, serotype $O$ and A, vaccine candidate.

\section{Introduction}

Foot-and-mouth disease (FMD) is a highly contagious disease of transboundary importance that affects more than 70 species of wild and domesticated cloven-hoofed animals globally [1]. It causes a devastating economic loss in food security, job loss and trade restrictions to the livestock industries in the endemic countries worldwide [2]. Furthermore, FMD is a matter of global animal health concern due to its transboundary nature and recent invasive outbreaks in the FMD-free countries like the United Kingdom in 2001 [3, 4], Japan in 2010 [5-7], China 2010 [8] and South Korea 2010 [9].

FMD virus (FMDV) is a member of the picornaviridae family possessing a positive-sense singlestranded RNA genome. Seven antigenically distinct serotypes of FMDV (namely O, A, C, Asia1, Southern African Territories (SAT) 1, 2 and 3) are circulating across the world with diverse subtypes like lineages, sublineages and topotypes [10]. Serotypes O, A, and Asial have had a worldwide dominant distribution along with continuous evolution and phylogenic differentiation [11]. Specifically, serotype O viruses are responsible for the majority of the outbreaks globally, followed by serotype A. Thus these two serotypes warrant special efforts to reduce the global burden of FMD [12]. Also, these two serotypes encounter a higher rate of mutations resulting in the evolutionary diversification of taxonomic groups.

The capsid of FMDV is composed of four structural proteins (VP1, VP2, VP3 and VP4). VP1 comprises the crucial epitopes for viral entry and subsequent lysis of infected host cells [13]. Notably, the G-H loop (aa positions 134-160) and the B-C loop (aa position: 40-60) of VP1 are critical for eliciting neutralizing antibodies against FMDV in the infected hosts [14]. The highly conserved RGD (Arg-Gly-Asp) motif within the VP1 G-H loop plays a significant role in viral entry into host cells and protective immunity in the host [15-17]. Due to rapid mutations in the surface regions of FMDV, especially within the immunogenically critical loops of VP1, an antigenic mismatch occurs between vaccine and field strains within the same serotypes, even some times, within the same lineages and sub-lineages that ultimately result in vaccine failure [18, 19]. 
Recently, Al Amin et al. reported the development of trivalent inactivated FMD vaccine composed of newly emerged global strains of each serotype [20-23]. Several limitations of inactivated whole virus vaccine pose potential threats towards its acceptability. The possibility of virus escape during production, inactivation and subsequent storage and transport conditions imposes potential hazards for inactivated virus vaccine manufacturers [24]. Removing non-structural peptides (NSPs) from purified antigen preparations is crucial for pre- and post-vaccination differentiation of infected and vaccinated animals. Reportedly, the cross-protection deficiencies among FMDV serotypes, intraserotype diversity and antigenic mismatch can contribute to emergence of vaccine-escape field strains[18,25], which necessitates the frequent reconditioning of vaccine strains to defend the most recently emerged strains of FMDV in susceptible areas. Emergence of phylogenetically distinct subgroups and their country-wide transmission with poor-quality surveillance give rise to frequent vaccine failure in Bangladesh [26]. The emergence of two novel sub-lineages Ind2001BD1 and Ind2001BD2 of serotype O, and a novel lineage BD-18 (G-IX) [22, 27] strongly indicates the necessity of FMD vaccine development with potential immunogenicity against both of the recently emerged and previously reported endemic strains of dominant serotype $\mathrm{O}$ and A. Interestingly, serotype O strains of FMDV which are genotypically very closely related to the Ind2001BD1 sublineage, have been reported from China, revealing the transboundary prevalence of the newly emerged strains [28]. A report of a recent FMD outbreak in vaccinated cattle in Eastern Saudia Arabia showed the prevalence of serotype O strains of $98 \%$ similarity with the novel sub-lineage [29], indicating lack of sero-protection from the vaccine strains differing by $11 \%$ sequence dissimilarities. In serotype A, the most antigenically divergent type, vaccine mismatch found between the vaccine strain and the field viruses from the same sub-lineage C (a subgroup of VP3 ${ }^{\Delta 59}$ variant) under the lineage A/ASIA/G-VII in Bangladesh [18]. Moreover, previously in India, vaccine mismatch due to antigenic drift in serotype A field viruses from the existing Indian vaccine strain IND 40/2000 of the same serotype was reported [30]. Thus, to combat the repetitive incidence of FMDV by diverse strains of serotype $\mathrm{O}$ and serotype $\mathrm{A}$, it is necessary to develop a single platform comprising the immunogenic capacity against most of the circulating strains throughout this territory [31].

FAO and OIE jointly proposed a 5-stage Progressive Control Pathway for Foot-and-mouth disease (PCP-FMD) for assisting and facilitating FMD endemic countries or regions like Bangladesh. The Government of Bangladesh (GoB) aims to reduce the impact of FMD progressively and towards 
eradicating the disease through strategic implementation of mass vaccination by inactivated whole virus. Recent advancements in FMD vaccine development strategy in the south Asian territories includes recombinant subunit vaccine based on VP1 sequence of vaccine strains isolated more than a decade ago [31]. Incorporation of protective antigen sequence in various types of vectors have been performed using pandemic strains which are evolutionarily distant from the FMDV strains circulating since last ten years. The lack of vaccine strain amelioration along with underestimation of their antigenic heterogeneity has led to vaccine failure and transboundary transmission of FMDV [26].

For these reasons, many research groups worldwide are investigating scopes of developing alternative effective vaccine approaches for FMD [32]. Epitope-based vaccines are emerging as promising candidates for future vaccines due to the absence of any risks of virus replication, the capability to function as DIVA vaccines, devoid of any residual peptides from whole viruses, and the combination of multiple epitopes on a single polypeptide platform [33]. As previously mentioned, VP1 possesses multiple conformational B-cell epitopes located in the G-H loop, B-C loop and C-terminal (aa positions: 190-210 approximately), it is highly crucial for the selection of antigenic fragments to design multiple epitope-based vaccine candidates $[34,35]$. These epitopes are located in receptor binding sites of VP1 and can elicit humoral responses in infected animals. Several artificial vaccines based on epitopes from the G-H loop of VP1 of FMDV have shown neutralizing efficiency in guinea pigs, swine, etc. [36-38]. However, none of these endeavors incorporated the epitopes from the novel lineages and sub-lineages that emerged in Bangladesh and spread over many other countries.

Thus, in this study, we have designed two complete artificial chimeric peptides, named as B1 and B3, composed of the surface epitope fragments, GH loop and C terminal of VP1 capsid peptides, of circulating FMDV serotype O (B1) and A (B3) strains, representing the different clusters of their phylogroups. The recombinant peptides possess conformational B-cell epitopes, like GH loop and C-terminal, and two crucial T-cell epitopes that are assumed to enhance T-cell dependent immunity and cytotoxic T-cell proliferation. Also, two universal T cell epitopes, PADRE (Panhuman leukocyte Antigen DR-binding Epitope) and Invasin, have been included to further enhance $\mathrm{T}$ cell activity and memory cell development for long term immunity [36, 39, 40]. The chimeric peptides have been efficiently expressed in a prokaryotic system with significant yield and 
conformational stability. Guinea pig models have been immunized with the vaccines formulated with the chimeric peptides B1 and B3. Serological assays exhibited broad neutralizing efficacy of the vaccines of B1 and B3 against the viruses, including the newly emerged strains in the recent years, of serotypes $\mathrm{O}$ and $\mathrm{A}$, respectively, in Bangladesh.

\section{Materials and Methods}

\subsection{Designing and in silico analysis of Chimeric Peptides B1 and B3}

\subsubsection{Construction of chimera B1 and B3}

During this study, emphasis has been given to predominantly FMDV serotype $\mathrm{O}$ and serotype A, mainly circulating in Bangladesh. A total of forty VP1 nucleotide sequences from serotype O and twelve from serotype A sequence data of FMDV (Supplementary Table 1 and 2) were obtained from the National Center for Biotechnology Information [NCBI] GenBank sequence database [41]. These sequences were obtained from FMDV strains isolated from Bangladesh previously by the Microbial Genetics and Bioinformatics lab (MGBL-109) of the Department of Microbiology, University of Dhaka (www.microbialgen.du.ac.bd). After multiple sequence alignment, peptides variability analysis (Supplementary Figure- 1) and phylogenetic relationship detection, several groups with different sequence homology in VP1 regions were revealed. From those groups, two types of fragments, G-H loop fragment (aa 128-164) and C-terminal fragment (aa 190-211), were selected as conformational B-cell epitopes to construct two multi-epitope recombinant peptides, namely B1 and B3. As illustrated in tables 1 and 2, six G-H loop fragments and three C-terminal fragments were oriented along with two T-cell epitopes, one from the N-terminal of VP1 and another from 3A peptides of FMDV strains. In both B1 and B3 constructs, two universal T-cell epitopes, 12 amino acid long PADRE (Pan-human leukocyte Antigen DR-binding Epitope) and 16 amino acids long Invasin (from Yersinia), were included at 5' and 3' of both chimeras. The GEDG spacer sequence differentiated each epitope of B1 for proper spatial orientation of all immunogenic fragments. In B3, four spacer sequences were GEDC, and the rest eight spacers were GEDG. Subsequently, the DNA sequence encoding both B1 and B3 were obtained by reverse genetics tools. Codon optimization is very crucial for the heterologous expression of eukaryotic pathogenic peptides through the bacterial system. B1 and B3 encoding DNA were optimized for codon usage using the OptimumGene algorithm to ensure the influences of the factors like codon 
usage bias, mRNA secondary structure, ribosomal binding sites, repeat sequences and restriction sites etc. Optimization of these parameters ensures a significant level of heterologous expression of both B1 and B3.

\subsubsection{Prediction and analysis secondary and tertiary structures of B1 and B3}

The Mfold Web-based software (mfold.rna.albany.edu) was used to analyze the structures of folding messengers RNAs of the chimeric genes [42], whereas the RNAfold (rna.tbi.univie.ac.at) and Genesee (www.genebee.msu.su/services/ rna2_reduced.html)online server revealed the energetic stability of the predicted structures. Results were confirmed by CentroidFold Web Server, which indicated the mRNA was stable enough for effectual translation in the prokaryotic host [43]. GOR-IV (gor.bb.iastate.edu/) [44] and Jpred 4 (compbio.dundee.ac.UK/jpred/) [45] online servers were used for prediction of secondary structure of B1and B3 peptide. In order to analyze the sequence and predict the peptides structures and functions, the percentage of random coils, alpha-helices and beta-sheets, the solvent accessibility were evaluated by the PredictPeptides server [46].

3D structures of $\mathrm{B} 1$ and $\mathrm{B} 3$ were predicted based on amino acid sequences using the PONDEROSA-C/S, a server-based software package for automated peptides 3D structure determination. Results were examined by using Ponderosa Analyzer. The relevant results were viewed with PyMOL molecular graphics systems [47, 48]. 3D structures were evaluated using Ramachandran Plot Analysis [49]. Various physical and chemical parameters of B1 and B3 were computed (Supplementary table- 4) using ExPASy - ProtParam tool [50].

\subsection{Synthesis, Expression and Characterization of Recombinant Chimeric Peptides B1 and B3}

\subsubsection{Transformation and expression of B1 and B3}

The codon-optimized DNA constructs of B1 and B3 were then commercially synthesized from GenScript (www.genscript.com) with two restriction sites EcoRl and Hindlll, respectively, at 5' and 3 ' end of both chimeric peptidespeptides' sequences. The artificial DNA fragments were inserted into the pET21a+ vector (Supplementary Figure- 2) at the respective restriction site to produce recombinant plasmids $\mathrm{pET} 21 \mathrm{a}+\mathrm{B} 1$ and $\mathrm{pET} 21 \mathrm{a}+\mathrm{B} 3$. The $\mathrm{pET}-21 \mathrm{a}(+)$ vector carries an 
N-terminal T7-Tag sequence plus a C-terminal His-Tag sequence. The frameshifting was also checked before performing the cloning reaction. The freeze-dried recombinant plasmids pET21a+/B1 and pET21a+/B3 were reconstituted according to the manufacturer's protocol. Both recombinant plasmids $\mathrm{pET} 21 \mathrm{a}+\mathrm{B} 1$ and $\mathrm{pET} 21 \mathrm{a}+\mathrm{B} 3$ were transformed into chemically competent $D H 5 \alpha$ cells for propagation. The plasmids were purified by PureYield ${ }^{\mathrm{TM}}$ Plasmid Miniprep System (Promega, USA). The molecular weight of the recombinant plasmid was detected by agarose gel electrophoresis. The purified plasmids were further transformed into chemically competent BL21(DE3) cells using the heat-shock process, and starter cultures were developed from transformed colonies isolated from ampicillin containing LB medium. Expression was induced in LB broth containing 1\% glucose when OD $_{600}$ reached 0.4-0.6. $1 \mathrm{mM}$ IPTG was added for induction, and the $50 \mathrm{ml}$ culture was incubated at $37^{\circ} \mathrm{C}$ in a shaker at $150 \mathrm{rpm}$ for 4 hours. No IPTG solution was added to the control sample but was also incubated with the test sample. After induction, all cultures were transferred to $50 \mathrm{~mL}$ falcons and cells were harvested by high-speed centrifugation. The harvested cells were then resuspended in PBS and kept at $-80^{\circ} \mathrm{C}$ overnight.

\subsubsection{Extraction, Purification and Quantification of chimeric B1 and B3}

The next day, the harvested cells were subjected to one freeze-thaw cycle followed by sonication $(100 \mathrm{~W}, 10 \mathrm{~s}$ pulse, $5 \mathrm{~min}$ ) for cell lysis and extraction of total peptides. After sonication, centrifugation was done to separate soluble and insoluble fractions at 14,000 rpm for 15 minutes at $4^{\circ} \mathrm{C}$. The peptides expression was first asses through SDS-PAGE analysis of total extracts of all induced and control cells. According to the manufacturer's protocol, each of the insoluble fractions, i.e.the pellets, were subjected to peptides purification under denaturing conditions by HisPur ${ }^{\mathrm{TM}}$ Ni-NTA Resin (Thermo Scientific, USA). The final elution was performed with $500 \mathrm{mM}$ imidazole, and further desalting the eluted fractions removed the imidazole and exchanged the buffer with PBS (pH 7.4; Gibco). The purified peptides were quantified by Bradford Assay and stored at -80 until further use.

\subsection{Characterization of Expressed B1 and B3 Peptides}

The molecular weights of purified B1 and B3 were determined by $12.5 \%$ SDS-PAGE using the Mini-PROTEAN system (Biorad). The molecular weight of B1 and B3 revealed $41.0 \mathrm{kDa}$ and 39.3 KDa, respectively, which is very close to the predicted MW of both. The presence of a $6 \mathrm{X}-$ 
Histidine tag at the C-terminal of purified peptides B1 and B3 were also confirmed by western blot techniques. $2 \mu \mathrm{g}$ of purified peptides were separated by SDS-PAGE using $12.5 \%$ polyacrylamide gels. The separated peptides were transferred to a nitrocellulose membrane, $0.45 \mu \mathrm{m}$ (BIO-RAD) using Trans-Blot ${ }^{\circledR}$ SD Semi-Dry Transfer Cell (BIO-RAD). The membranes were incubated for 1 hour with SuperBlock ${ }^{\mathrm{TM}}$ Blocking Buffer (Thermo Scientific, USA) at room temperature with moderate shaking. Then membranes were incubated with primary antibody, 6$\mathrm{X}$ His Tag mouse monoclonal antibody (Invitrogen) at a dilution of 1:1000 for 1 hour at room temperature in a mini-rocker. After washing the membrane five times ( 5 minutes each) with $0.1 \%$ TBS-T, the membrane was incubated with HRP-conjugated Goat anti-mouse secondary antibody (Thermo Scientific, USA) (at a dilution of 1:10,000) directed against the primary antibody. The washing step was repeated five times. SuperSignal ${ }^{\mathrm{TM}}$ West Pico PLUS Chemiluminescent Substrate (Thermo Scientific, USA) was used for detection according to the manufacturer's protocol, and the final images were taken in ChemiDoc Imaging System (Biorad). Furthermore, the WB method has confirmed the presence of antigenic fragments on the purified peptides using serotype-specific monovalent anti-FMDV bovine serum as primary antibody and anti-bovine goat antibody (HRP) as the secondary antibody. These WB images showed a positive reaction with both peptides with respective anti-FMDV bovine serum.

\subsection{Immunogenicity testing of Chimeric B1 and B3}

\subsubsection{Experimental animals and viruses}

For immunogenicity assessment of the recombinant peptides, a total of forty-nine Dunken-Hartley strains of guinea pig animal models (bodyweight 350-450 gm) were used for immunization experiments. All experimental works were performed in the Animal Resource Facility of International Centre for Diarrheal Disease Research, Bangladesh (icddr'b). Animal handling for immunization and blood collection was performed according to the guidelines prescribed by the Ethical Review Committee of the University of Dhaka. Ethical clearance (Ref.: 66/Biol.Scs/20182019; Date: 14-11-2018; Supplementary Figure-4) for the research works was obtained from the Ethical Review Committee, the University of Dhaka, approved by Animal Resource Facility (ARF), ICDDR'B.

For assessment of virus neutralization efficiency of the chimeric peptides, two recently reported vaccine FMDV strain for both serotype O (BAN/TA/Dh-301/2016) and serotype A (BAN/CH/Sa- 
304/2016) have been collected from the repository of MGBL and revived using BHK-21 cell line. The infectivity and tissue culture infective dose 50 (TCID 50$)$ were determined for each strain. Besides, four other strains, previously collected from field samples in Bangladesh, were also revived: BAN/NA/Ha-156/2013, BAN/BO/Na-161/2013, BAN/DH/Sa-310/2017 and BAN/GA/Sa-197/2013.

\subsubsection{Antigen preparation}

For the two recombinant peptides, four different concentrations of each antigen were inoculated in different groups of experimental guinea pigs. The doses were 100, 50, 10 and $2 \mu \mathrm{g} / \mathrm{dose}$ of antigen. The purified peptides were diluted in PBS (pH 7.4) and mixed with adjuvant Montanide 201 in a 1:1 (w/w) ratio. The final peptides concentrations in the formulated antigen were obtained as 100,50,10 and $2 \mu \mathrm{g}$ per $1.0 \mathrm{ml}$ antigen dose. Eight antigen formulations were prepared, four of which were $\mathrm{B} 1$ and others were $\mathrm{B} 3$. The antigen preparations were kept at $4^{\circ} \mathrm{C}$ and carried to $\mathrm{ARF}$, ICDDR'B, using a proper cool-box.

\subsubsection{Immunization of Guinea Pigs}

Forty-nine guinea pigs were divided into two groups, nine in the control group and forty in the experimental group. Forty GPs were further divided into eight groups (A-H), five in each, whereas nine GPs of the control group were divided into three (X, Y and Z) groups, three in each (Supplementary Table- 3). Four experimental groups of GPs were inoculated with four antigen preparations of B1, and the other four groups were immunized for antigen preparation of B3. 1.0 $\mathrm{ml}$ of each antigen were injected subcutaneously in each GP. The control groups $\mathrm{X}$ and $\mathrm{Y}$ were inoculated with inactivated monovalent FMDV vaccine types $\mathrm{O}$ and $\mathrm{A}$. These vaccines were prepared from the two recently reported vaccine strains BAN/TA/Dh-301/2016 (serotype-O) and BAN/CH/Sa-304/2016 (serotype-A) [21, 23]. The control group-Z were inoculated with only 1.0 $\mathrm{ml}$ PBS, mixed with an adjuvant. The booster immunization was performed on day 14 with similar antigens in each group. All the animals were sacrificed on day-28, and blood was collected aseptically by direct cardiac puncture. Serum samples were prepared from the blood samples of each animal by centrifugation and were stored until further use. 


\subsubsection{Detection of anti-B1 and anti-B3 antibody in GP serum}

The presence of antibodies in the polyclonal GP serum was determined by western blotting the B1 and B3 antigens. The WB analysis of B1 was performed using both anti-B1 sera and serum of control group-X. Similarly, B3 was blotted by anti-B3 serum and control group-Y serum. Goat anti-Guinea Pig IgG antibody (Invitrogen, USA) was used as secondary antibody and SuperSignal WestPico PLUS Chemiluminescent Substrate and ChemiDoc Imaging System were used for image development.

\subsubsection{Virus Neutralization Tests}

To determine each group's neutralizing antibody titer in serum, virus neutralization tests (VNT) have been performed on monolayers of BHK-21 cells using Karber Method [51] 100TCID 50 of BAN/TA/Dh-301/2016 (serotype-O) strain was used to quantify $\mathrm{SN}_{50}$ titer animals immunized with different concentrations of B1 antigen, and BAN/CH/Sa-304/2016 (serotype-A) was used for B3 antigens. The neutralizing efficiency of $100 \mu \mathrm{g} /$ dose of B1 antigen (group A) was further assayed using serotype-O strains BAN/NA/Ha-156/2013 and BAN/BO/Na-161/2013. In contrast, the efficiency of group-E $(100 \mu \mathrm{g} / \mathrm{dose}$ of B3) was assayed using serotype-A strains BAN/DH/Sa310/2017 and BAN/GA/Sa-197/2013. The neutralizing antibody titers were expressed as the $\log 10$ value of the reciprocal of the last dilution that neutralized 100 tissue culture infective dose $50 \%$ (TCID50) of FMDV in 50\% of the wells. All control serum was also tested for determining the $\mathrm{SN}_{50}$ titer similarly. To detect the protective titer for FMDV strains, the $\mathrm{SN}_{50}$ titer above 1.2 has been considered effective, which was shown in previous reports recognizing the anti-FMDV immune response of guinea pigs as a model for evaluation of vaccine potency in cattle [52, 53].

\subsubsection{Statistical Analysis}

Statistical analyses of all the raw data of the experiment were performed in $\mathrm{R}$ software version 4.0.5 [54] and the graphs were built in ggplot2, an open-source R package [55]. We used the oneway ANOVA test to compare the antibody titers raised among the different vaccination doses. When the overall difference across the overall groups was significant, we computed Tukey HSD (Tukey Honest Significant Differences, R function: TukeyHSD()) for performing multiple pairwise-comparison between the means of groups. The function TukeyHSD () takes the fitted 
ANOVA as an argument. Analyses were carried out at a 95\% confidence level and p-values less than 0.05 were considered as statically significant.

\section{Results}

\subsection{Designing of Chimeric Peptides of FMDV Serotype-O}

\subsubsection{In silico construction and analysis of multi-epitope recombinant peptides B1 and B3}

To construct the chimeric vaccine candidates, B1 and B3, multiple B-cell epitopes and T-cell epitopes were selected from the variable regions of VP1 capsid proteins of FMDV serotype $\mathrm{O}$ and A, respectively. For B-cell epitopes, both the GH-loop region (aa 128-164) and C-terminal region (aa 190-211) of VP1 were included in B1 chimera from BAN/TA/Dh-301/2016, BAN/MG/Sa287/2016 and BAN/TA/Ma-200/2014, sequences have been taken from C1, C2 and C3 clusters respectively (Fig. 1A). For T-cell epitopes, two epitopes were included, one of which is in the Nterminal region (aa 25-36 for type-O and aa 29-37 for type-A) of VP1 (Figure 2A), and the other one is in the 3A protein region of FMDV (Table 1 and 2). The GEDG spacer between each epitope enhanced the acidic and basic amino acid ratio in the final B1 construct, stabilizing the solubility and cytosolic conformation. 

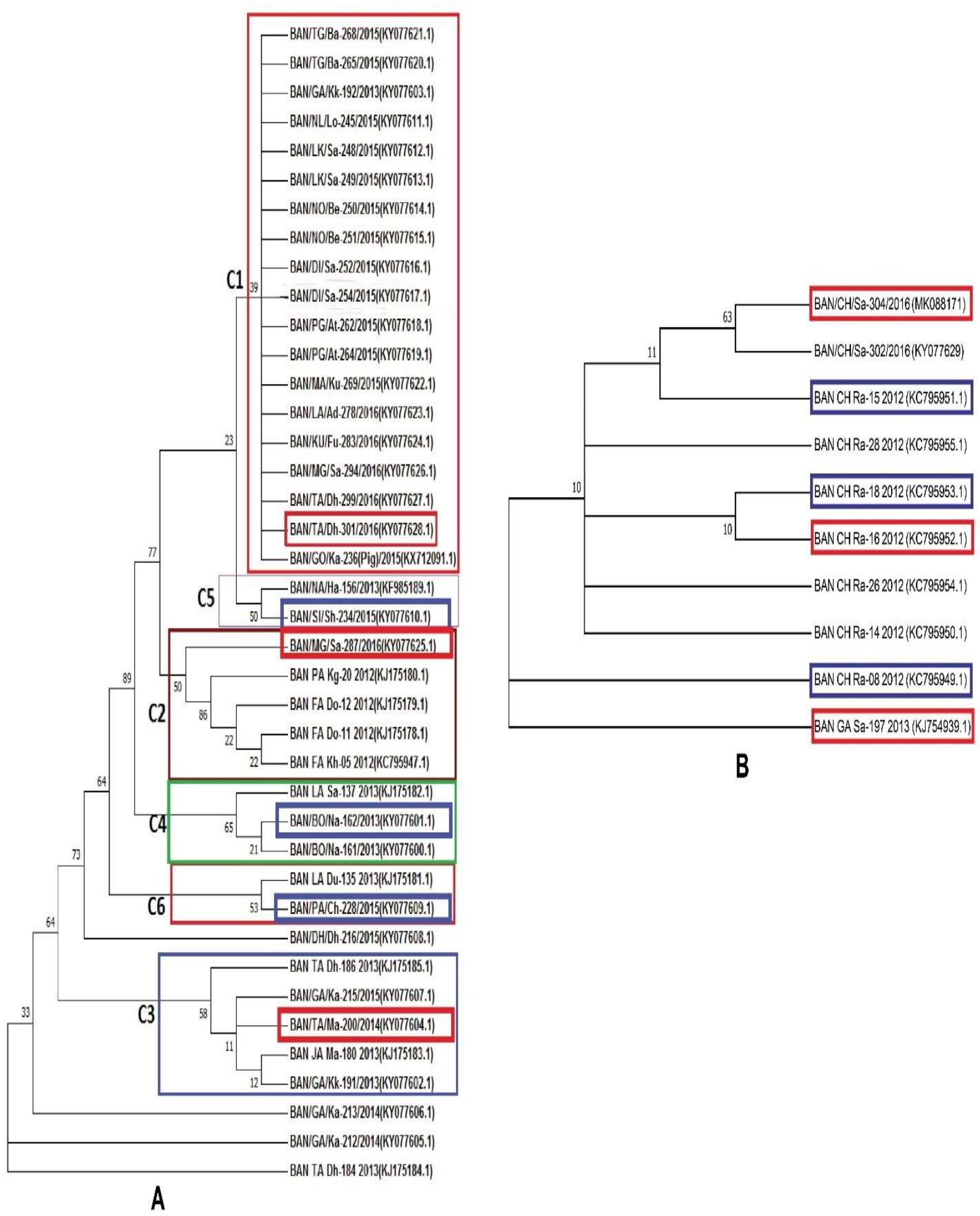

Fig. 1: Phylogenetic analyses for variant selection to construct multiepitope chimeric peptides of FMDV serotype $O$ and serotype A. (A) Phylogenetic analysis of VP1 (121-211 amino acid 
residues) of 40 Foot-and-Mouth Diseases Virus (FMDV) type O circulating in Bangladesh from 2012-2016. The prototype sequences are induced from GenBank. The tree was inferred using neighbour-joining method and simulation with 1000 bootstrap replication value. The tree was condensed with 5\% cut off value. The phylogenetic analysis was directed in MEGA-7.0 Phylogenetic tree has enabled us to differentiate 6 clusters. C1 cluster contains 19 sequences, C2 contains 5 sequences, C3 contains 5 sequences, C4 contains 3 sequences, C5 contains 2 sequences and C6 contains 2 sequences. There are also 4 sequences, those do not form cluster. Representative sequences selection from phylogenetic tree for recombinant peptides. BAN/TA/Dh-301/2016, BAN/MG/Sa-287/2016 and BAN/TA/Ma-200/2014, lineages have been taken from C1, C2 and C3 clusters respectively (red marking). BAN/BO/Na-162/2013, BAN/SI/Sh-234/2015 and BAN/PA/Ch-228/2015 lineages have been taken from C4, C5 and C6 clusters respectively (blue marking). From cluster C1, C2 and C3, both $\mathrm{G}-\mathrm{H}$ loop and C-termini have been taken for recombinant peptides. From $\mathrm{C} 4, \mathrm{C} 5$ and $\mathrm{C} 6$, only $\mathrm{G}-\mathrm{H}$ loop has been taken to construct recombinant peptides. (B) Phylogenetic tree of the serotype A was also constracted as the same way described above and the representative $G$-H loop amd $C$-terminal (red marked) and only $G$ H loop (blue marked) were taken for cheimeric peptides reconnstruction.

In serotype-A specific chimera B3, a phylogenetic tree was constructed, including GH loop and C-terminal sequence of VP1. For inclusion in B3 chimera, the representative G-H loop and Cterminal both (BAN/CH/Sa-304/2016, BAN/CH/Ra-16/2012, BAN/GA/Sa-197/2013) and only G-H loop (BAN/CH/Ra-15/2012, BAN/CH/Ra-18/2012, BAN/CH/Ra-08/2012) epitopes were selected (Figure 1B). For lack of Cysteine in the epitopes of serotype A strains, the GEDC spacer is inserted in four positions in the B3 construct, keeping the rest spacers GEDG (Figure 2D).

The universal T-cell epitopes, PADRE and Invasin, were inserted at the N-terminal and C-terminal positions of both B1 and B3 constructs (Figure 2A and 2D). The computational analysis of DNA encoding B1 and B3 revealed that the gene length is $1170 \mathrm{bp}$ and $1149 \mathrm{bp}$ long. The molecular weight of $\mathrm{B} 1$ and $\mathrm{B} 3$ were $41.0 \mathrm{kDa}$ and $39.0 \mathrm{kDa}$, with the predicted isoelectric points 7.7 and 8.5 . 
Table 1: Source of G-H loop, C-terminus of the VP1 peptides from circulating FMDV serotype O strains and universal T-cell epitopes

\begin{tabular}{|c|c|c|}
\hline Epitopes & Peptides Sequences & Origin of epitopes \\
\hline PADRE & AKFVAAWTLKAAA & Universal T-cell epitopes [39] \\
\hline $\begin{array}{l}\text { VP1(128- } \\
164)\end{array}$ & TVYNGNCKYGEGAVTNVRGDLQVLAQKATRTLPTSFN & $\begin{array}{l}\text { G-H loop of BAN/TA/Dh- } \\
301 / 2016\end{array}$ \\
\hline NTTCE & VTPQNQINVL & $\begin{array}{l}\text { N-terminal T cell } \\
\text { epitopes of type } O \text { [13] }\end{array}$ \\
\hline $\begin{array}{l}\text { VP1(128- } \\
164)\end{array}$ & TVYNGNCKYGEGAVTNVRGDLQVLAQKATRTLPTSFN & $\begin{array}{l}\text { G-H loop of BAN/SI/Sh- } \\
234 / 2015\end{array}$ \\
\hline $\begin{array}{l}\text { VP1(190- } \\
\text { 211) }\end{array}$ & PLLAIHPEQARHKQKIVAPVKQ & $\begin{array}{l}\text { C-terminal of BAN/TA/Dh- } \\
301 / 2016\end{array}$ \\
\hline $\begin{array}{l}\text { VP1(128- } \\
164)\end{array}$ & TVYNGNCKYGESNVPNVRGDLQVLAQKAARPLPTSFN & $\begin{array}{l}\text { G-H loop of BAN/TA/Ma- } \\
200 / 2014\end{array}$ \\
\hline $\begin{array}{l}\text { VP1(190- } \\
\text { 211) }\end{array}$ & PLLAIHPSEARHKQKIVAPVKQ- & $\begin{array}{l}\text { C-terminal of BAN/TA/Ma- } \\
200 / 2014 \\
\end{array}$ \\
\hline $\begin{array}{l}\text { VP1(128- } \\
164)\end{array}$ & TVYNGNCKYGEGAVTNVRGDLQVLAQKAARTLPTSFN & $\begin{array}{l}\text { G-H loop of BAN/BO/Na- } \\
162 / 201\end{array}$ \\
\hline $\begin{array}{l}\text { VP1(190- } \\
\text { 211) }\end{array}$ & PLLAIHPGQARHKQKIVAPVKQ & $\begin{array}{l}\text { C-terminal of BAN/MG/Sa- } \\
287 / 2016\end{array}$ \\
\hline $\begin{array}{l}\text { VP1(128- } \\
164)\end{array}$ & TVYNGNCKYGEGAVTNVRGDLQVLAQKAARTLPTSFN & $\begin{array}{l}\text { G-H loop of BAN/MG/Sa- } \\
287 / 2016\end{array}$ \\
\hline $3 \mathrm{~A}$ & AAIEFFEGMVHDSIK & $\begin{array}{l}\text { Structural 3A peptides } \\
\text { T cells epitopes [13] }\end{array}$ \\
\hline $\begin{array}{l}\text { VP1(128- } \\
164)\end{array}$ & TVYNGNCKYGGSDVANVRGDLQVLAQKAARPLPTSFN & $\begin{array}{l}\text { G-H loop of BAN/PA/Ch- } \\
228 / 2015\end{array}$ \\
\hline Invasin & TAKSKKFPSYTATYQF & Universal T-cell epitopes [36] \\
\hline
\end{tabular}

respectively. For expression of the recombinant peptides in prokaryotic host BL-21(DE3), the codons of the encoding DNA fragments were optimized using the OptimumGene ${ }^{\mathrm{TM}}$ algorithm. The native genes employed rare tandem codons capable of reducing the efficiency and continuity of translation inside the cytoplasm. These were optimized with the inclusion of optimal codons, upgrading the Codon Adaptation Index (CAI), adjusting the GC content, and removing cis-acting elements from the transcripts. The codon optimization of $\mathrm{B} 1$ and $\mathrm{B} 3$ encoding sequences upgraded the CAI index to 0.85 and 0.87 , respectively. The average GC content of recombinant DNA fragments of B1 and B3 were adjusted to $58.13 \%$ and $60.20 \%$, respectively. The codon 
optimization also nullified the unfavorable peaks to prolong the mRNA half-life and disrupt stemloop structures to enhance the ribosomal binding and stability.

Table 2: Source of G-H loop, C-terminus of the VP1 peptides from circulating FMDV serotype A strains and universal T-cell epitopes

\begin{tabular}{|c|c|c|}
\hline Epitopes & Sequences of Epitope fragments & Origin of epitopes \\
\hline VP1(129-165) & VYNGTNKYSAASGRARGDLGQLAARVAAQLPASFNFG & $\begin{array}{l}\text { G-H loop of } \\
\text { BAN/CH/Sa-304/2016 }\end{array}$ \\
\hline NTTCE & VKIGNVSPT & $\begin{array}{l}\text { N-terminal T cell } \\
\text { epitopes of Type-A }\end{array}$ \\
\hline VP1(129-165) & VYNGTNKYSAASGRVRGDLGQLAARVAAQLPASFNFG & $\begin{array}{l}\text { G-H loop of } \\
\text { BAN_CH_Ra-15_2012 }\end{array}$ \\
\hline VP1(192-211) & AVEVSSQDRHKQKIIAPAKQ & $\begin{array}{l}\text { C-terminal of } \\
\text { BAN/CH/Sa-304/2016 }\end{array}$ \\
\hline VP1(129-165) & VYNGTNKYSAASGRVRGDLGQLAARVAAQLPASFNFG & $\begin{array}{l}\text { G-H loop of } \\
\text { BAN_CH_Ra-16_2012 }\end{array}$ \\
\hline VP1(192-211) & AVEVSSQDRHKQKIIAPAKQ & $\begin{array}{l}\text { C-terminal of } \\
\text { BAN_CH_Ra-16_2012 }\end{array}$ \\
\hline VP1(129-165) & VYNGTNKYSAASGRVRGDLEQLAARVAAQLPASFNFG & $\begin{array}{l}\text { G-H loop of } \\
\text { BAN_CH_Ra-18_2012 }\end{array}$ \\
\hline VP1(192-211) & AVEVLSQDRHKQKIIAPAKQ & $\begin{array}{l}\text { C-terminal of } \\
\text { BAN_GA_Sa-197_2013 }\end{array}$ \\
\hline VP1(129-165) & VYNGTNKYSAASGRVRGDLGQLAARVAAQLPASFNFG & $\begin{array}{l}\text { G-H loop of } \\
\text { BAN_GA_Sa-197_2013 }\end{array}$ \\
\hline $3 \mathrm{~A}$ & AAIEFFEGMVHDSIK & $\begin{array}{l}3 \mathrm{~A} \text { of structural peptides } \\
\text { [13] }\end{array}$ \\
\hline VP1(129-165) & VYNGTNKYSAASGRVRGDLGQLAARVAAQLPASFNFG & $\begin{array}{l}\text { G-H loop BAN_CH_Ra- } \\
08 \_2012\end{array}$ \\
\hline
\end{tabular}


PADRE - GEDG - G-H loop of BAN/TA/Dh-301/2016-GEDG - NTTCE - GEDG - G-H loop of BAN/SI/Sh-234/2015 - GEDG - C-terminal of BAN/TA/Dh-301/2016 - GEDG - G-H loop of

A BAN/TA/Ma-200/2014 - GEDG - C-terminal of BAN/TA/Ma-200/2014 - GEDG - G-H loop of BAN/BO/Na-162/2013 - GEDG - C-terminal of BAN/MG/Sa-287/2016 - GEDG - G-H loop of BAN/MG/Sa-287/2016 - GEDG - 3A - GEDG - G-H loop of BAN/PA/Ch-228/2015 - GEDG - Invasin
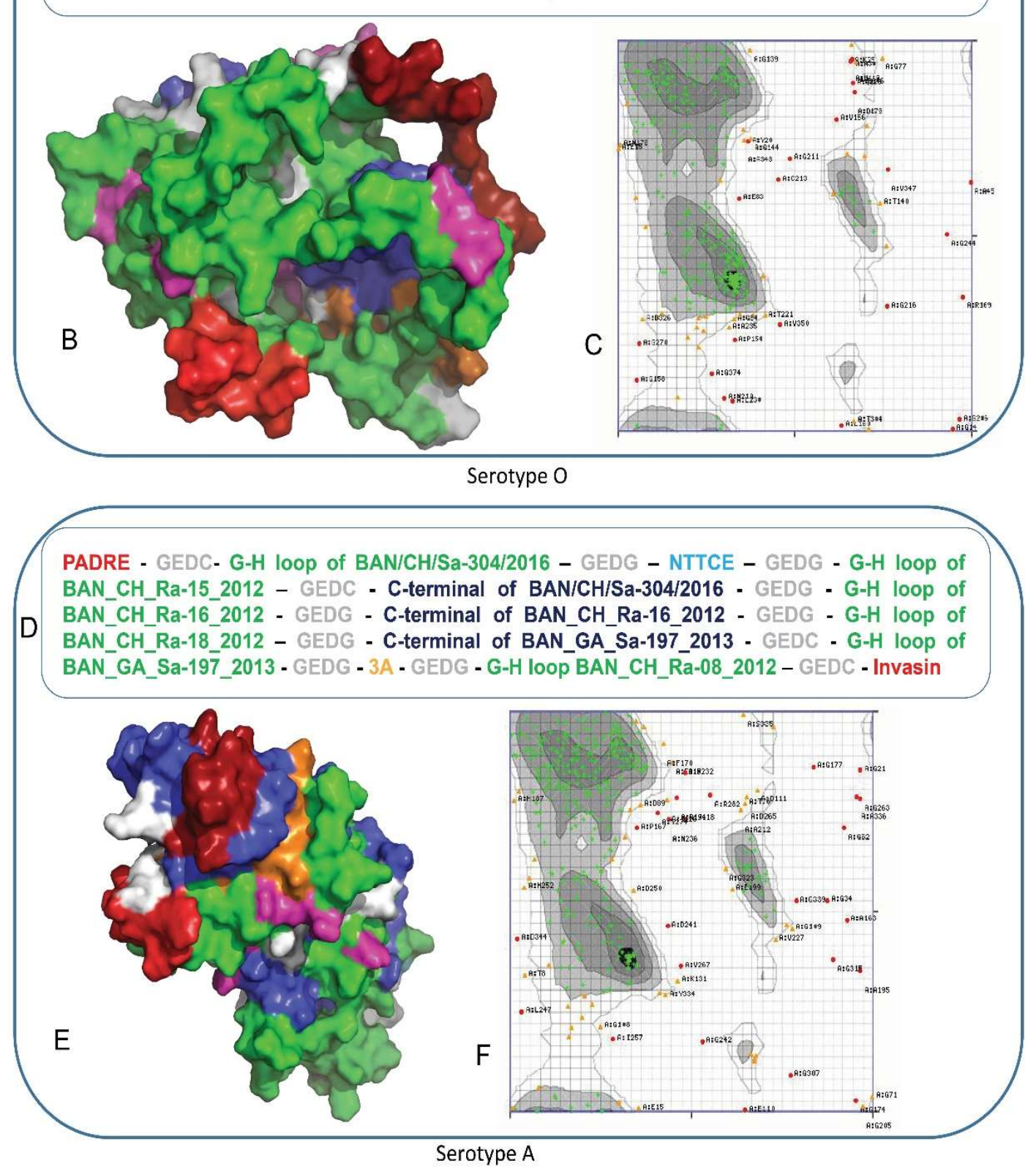

Fig. 2: Design, reconstruction and structural validation of multi-epitope chimeric peptides as a vaccine candidate for serotype $A$ and serotype $O$. (A) Orientation of epitopes with spacer to constract B1 multiepitope vaccine agaist serotype $O ;(B)$ terriary structure of $B 1$ and different 
colour represent different epitope. Here, Red represents PADRE, Invasin; Gray represents spacer; green represents $G$-H loops, blue represents $C$-terminal epitopes, cyan represents NTTCE, orange represents $3 A$ and finally megenta represents the RGD motifs of $G$-H loops. (C) Ramachandran plot of B1 to structural validation. This plot shows that $84.28 \%$ residues were in highly preferrd observaton as green crosses, $9.54 \%$ resdues were in preferrd observaton as brown crosses and rest $6.19 \%$ were in questionable observation as red crosses. (D) Orientation of epitopes with spacer to constract B3 multiepitope vaccine agaist serotype A. (E) terriary structure of B3 and different colour represent different epitope. Here, Red represents PADRE, Invasin; Gray represents spacer; green represents $G$-H loops, blue represents $C$-terminal epitopes, cyan represents NTTCE, orange represents $3 A$ and finally megenta represents the $R G D$ motifs of $G-H$ loops. (F) Ramachandran plot of B1 to structural validation. This plot shows that $80.58 \%$ residues were in highly preferrd observaton as green crosses, $12.60 \%$ resdues were in preferrd observaton as brown crosses and rest $6.82 \%$ were in questionable observation as red crosses.

\subsubsection{Prediction of Secondary and Tertiary Structures of the Recombinant Peptides}

The 'Mfold' server was used to evaluate the minimum free energy for chimeric mRNA of codonoptimized sequences. The results showed that the minimum free energy of the best predicted structure for the optimized B1 and B3 constructs were $-448.80 \mathrm{kcal} / \mathrm{mol}$ and $-466.30 \mathrm{kcal} / \mathrm{mol}$. The first nucleotides at 5' did not have a long stable hairpin or pseudoknot. Therefore, the binding of ribosomes to the translation initiation site and the following translation process can be readily accomplished in the target host. These outcomes were in agreement with data obtained from the 'RNAfold' web server. Several online programs were used to predict the secondary structures of the chimeric peptides, and GOR-IV achieved the best result. Results indicated that total residues of B1 were made up of 77 strands (19.74\%), 96 helices $(24.62 \%)$ and 217 random coils (55.64\%); whereas B3 contains 161 helices (42.04\%), 47 extended strands (12.27\%) and 175 random coils $(45.69 \%)$. 


\subsubsection{Prediction of 3D Structure and Physicochemical Parameters of the Recombinant Peptides}

B1 and B3 were composed of 390 and 383 amino acid residues encoded by 1170 and 1149 nucleotides sequences, respectively. The presence of the RGD motif on the surface of both recombinant peptides was evident when the 3D structures were analyzed using PyMOL. The presence of cysteine residues enhanced tertiary structure stability by forming disulfide bridges (Figure-2B and 2E). 3D Model of recombinant peptides was analyzed by Ramachandran Plot (Figure 2C and 2F), which showed more than $80 \%$ amino acid residues of both $\mathrm{B} 1$ and $\mathrm{B} 3$ reside in highly preferred region. Expasy's ProtParam classified the optimized chimeric peptides B1 and B3 as stable (Instability index: 18.83 and 19.61, respectively). Other basic Physico-chemical parameters of B1 and B3 chimeric peptides such as molecular weight was $41.3 \mathrm{kDa}$ and $39.3 \mathrm{kDa}$, respectively. The computed half-life for both peptides was greater than $10 \mathrm{hr}$. The in-silico predicted isoelectric point of B1 and B3 was determined respectively 7.7 and 8.5.

\subsection{Expression and analysis of $B 1$ and $B 3$ peptides}

\subsubsection{Expression, Purification and Characterization of the chimeric peptides B1 and B3}

The SDS-PAGE analysis of total cell extract of transformed and induced E. coli BL-21(DE3) cells revealed that both $\mathrm{B} 1$ and $\mathrm{B} 3$ had been expressed in the insoluble fraction of IPTG-induced cells. After purification and desalting, the molecular weight of both the chimera B1 and B3, confirmed by SDS-PAGE, was determined at $41.0 \mathrm{kDa}$ and $39.0 \mathrm{kDa}$, respectively (Figure $3 \mathrm{~A}$ ). The $6 \mathrm{X}$ Histidine tag on the C-terminal of the recombinant peptides was detected by Western blot (Figure 3B) using an anti-His mouse monoclonal antibody (Thermo, USA). 

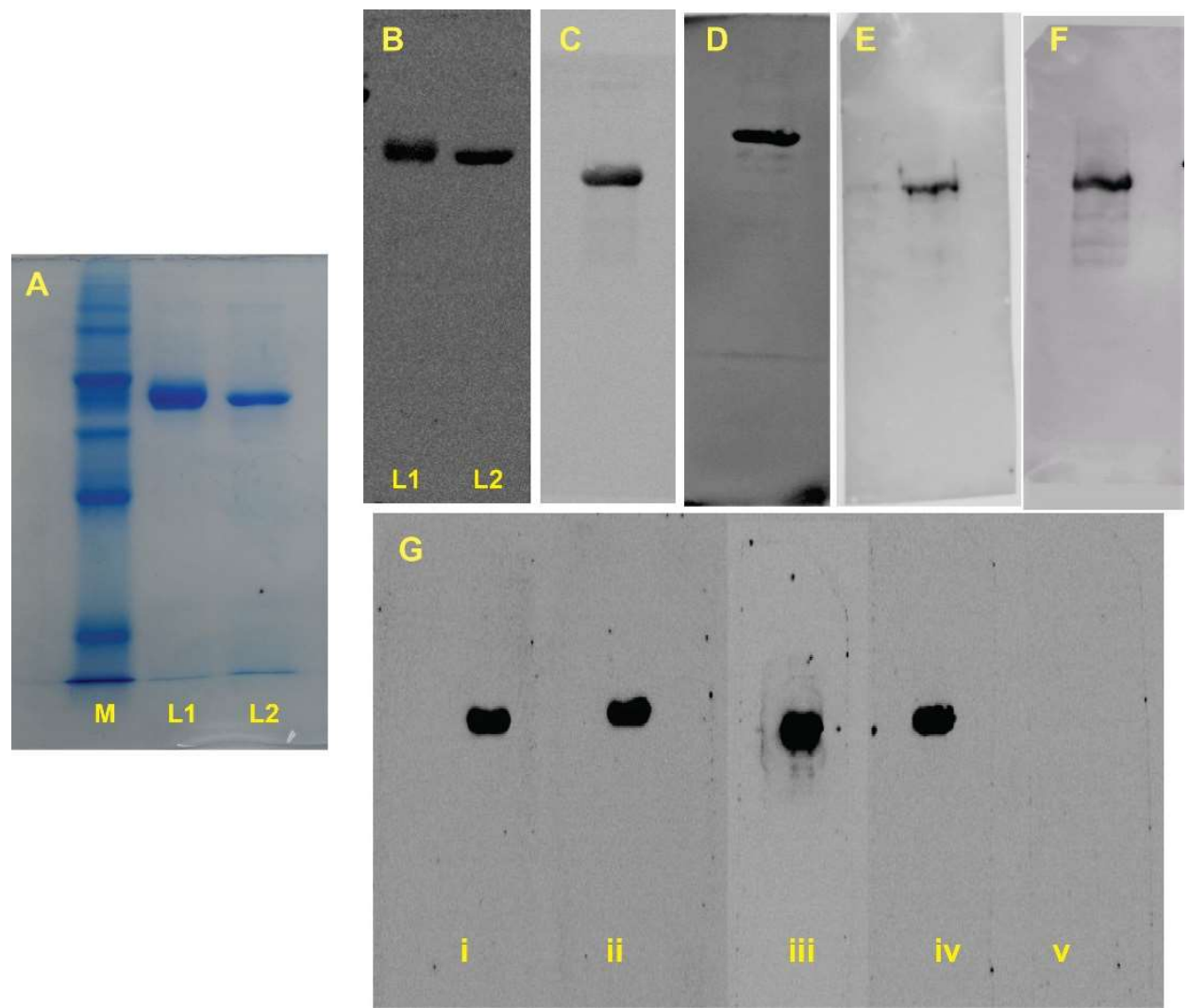

Figure-3: (A) SDS-PAGE detection of B1 (lane-1) and B3 (lane-2); M= $100 \mathrm{kDa}$ peptides marker. (B) Detection of 6X-his-tag on B1 (lane-1) and B3 (lane-2) by anti-His-monoclonal antibody. WB detection of (C)B1 by monovalent anti-FMDV-O and (D) B3 anti-FMDV-A bovine serum. WB detection of (E)B1 by monovalent anti-FMDV-O and $(F)$ B3 by anti-FMDV-A guinea pig serum. (G) WB detection of B1 from GP immunized with (i) $100 \mu \mathrm{g} /$ dose, (ii) $50 \mu \mathrm{g} /$ dose; B3 detected by

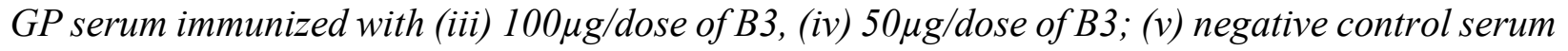
of GP immunized with PBS only. The monovalent guinea pig and bovine sera were developed by immunization with inactivated BAN/TA/Dh-301/2016 and BAN/CH/Sa-304/2016 vaccine strains, for serotype $O$ and $A$ respectively.

The surface antigens of FMDV, incorporated in B1 and B3, have also been detected in the chimeric peptides through western blot using monovalent anti-FMDV-O and anti-FMDV-A bovine serum, respectively (Figure 3C, D, E, F). These WB results indicated that the B-cell epitopes were surfaceoriented and readily recognizable by the protective antibodies present in anti-FMDV monovalent sera. Besides, WB of B1 and B3 antigens with homologous anti-B1 and anti-B3 GP sera showed 
that $\mathrm{B} 1$ reacts efficiently with anti-B1 sera from all antigen dose groups (group A-D) and serum of positive control (O-type, group-X) (Figure 3G). Similarly, B3 also reacted with anti-B3 serum and serum of control group Y (A-type positive control). The serum from negative control reacted with none of the antigens in WB experiments (Figure $3 \mathrm{G}$ ).

\subsubsection{Serum neutralization efficiency of $B 1$ and $B 3$ developed in the guinea pig models}

The virus neutralization tests with serum from animals immunized with different doses of B1 showed that the 100\% animals, immunized with both $100(\mathrm{Ag} \mathrm{B} 1 / \mathrm{A})$ and $50(\mathrm{AgB} 1 / \mathrm{B}) \mu \mathrm{g}$ dose, developed protective humoral response against the most recent vaccine strain BAN/TA/Dh$301 / 2016$. On the other hand, only $80 \%$ (4 out of 5) and $20 \%$ ( 1 out of 5 ) of animals developed protective levels of antibody from $10(\mathrm{AgB} 1 / \mathrm{C})$ and $2(\mathrm{Ag} \mathrm{B} 1 / \mathrm{D}) \mu \mathrm{g}$ dose of B1 antigen (Figure 4A). Besides, the SN50 titer of animal sera immunized with different doses of B3 antigen showed that animals immunized with $100(\mathrm{Ag} \mathrm{B} / \mathrm{E})$ and $50(\mathrm{AgB} 3 / \mathrm{F}) \mu \mathrm{g} / \mathrm{dose} \mathrm{B} 3$ antigen developed protective immune response in $100 \%$ and $80 \%$ animals of the respective group against the vaccine strain (BAN/CH/Sa-304/2016 for serotype-A (Figure 4D).

From the VN test with two other circulatory strains of each serotype, it has been revealed that the polyclonal serum from GPs immunized with 100 and $50 \mu \mathrm{g} /$ dose of both antigens, separately, has shown to develop protective immune responses. Specifically, the anti-B1 sera of $100 \mu \mathrm{g} / \mathrm{dose}$ showed the development of a protective antibody in $100 \%$ animals against both BAN/BO/Na156/2013 and BAN/NA/Ha-161/2013 strains (Figure 4b, 4C). In the case of B3 antigen, only strain BAN/DH/Sa-310/2017 has shown to be neutralized in VN test with anti-B3 sera from both 100 and $50 \mu \mathrm{g} / \mathrm{dose}$ B3 antigens (Figure 4E). One strain BAN/GA/Sa-197/2013 was neutralized neither by the inactivated monovalent type-A vaccine (positive control) nor by the B3 antigen (Figure 4F). 


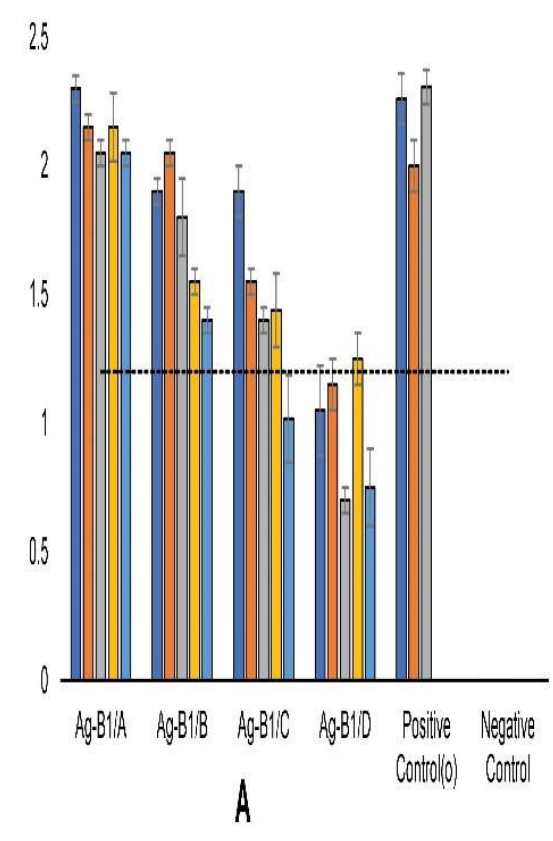

3
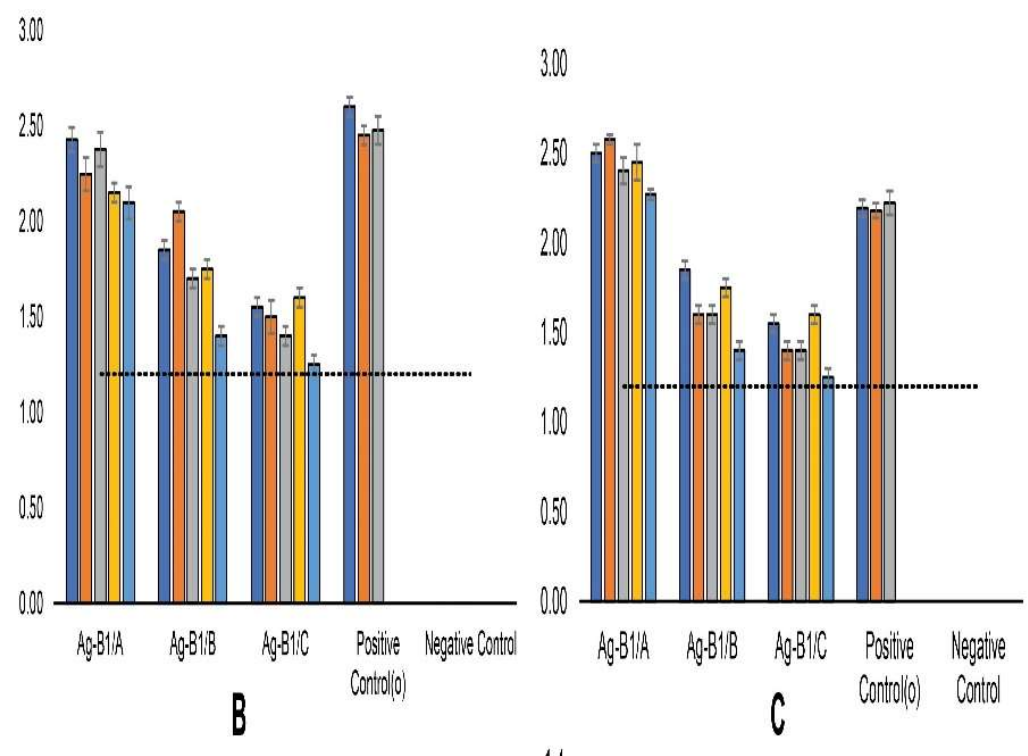

25

1.4
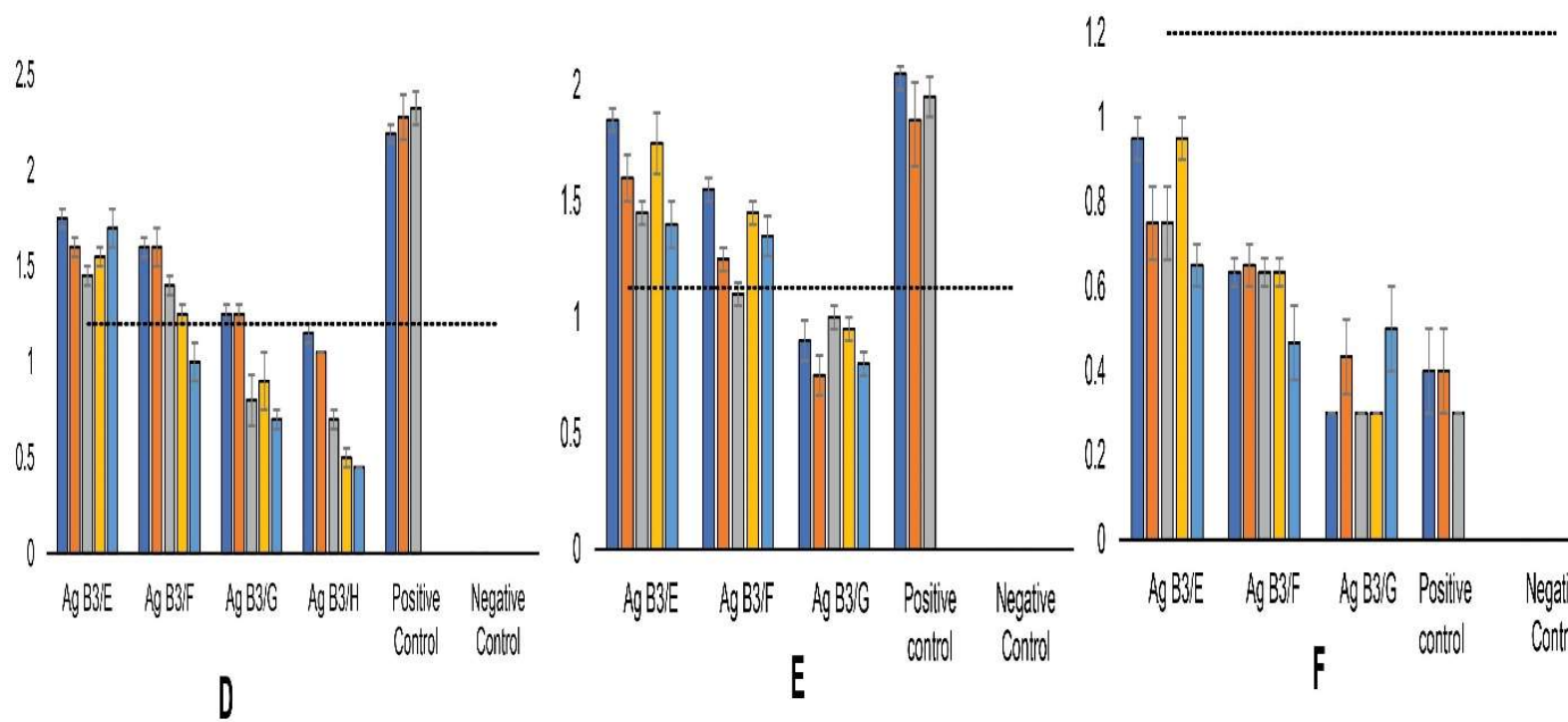

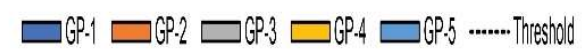

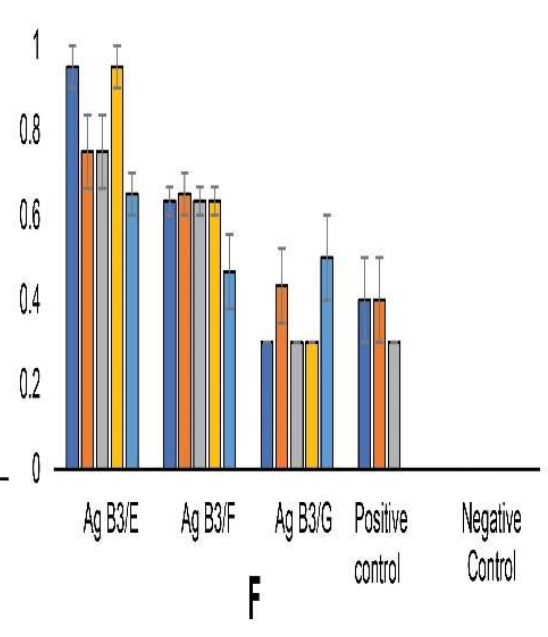

Fig. 4: SN50 Titer of IgG in anti-B1 serum against (A)BAN/TA/Dh-301/2016, (B)BAN/NA/Ha156/2013 and (C)BAN/BO/Na-161/2013. SN50 Titer of IgG in anti-B3 serum against (A)BAN/CH/Sa-304/2016, (E)BAN/DH/Sa-310/2017 and (F)BAN/GA/Sa-197/2013. The horizontal dashed line indicates the threshold antibody titer 1.2, where the antibody titers $\geq 1.2$ (log10) refer the protective level in guinea pig. Error bars represent standard error of the mean 
(SEM). The X-axis of the bar diagrams indicates GP groups immunized with different conc. Of B1 and B3. The $Y$-axis represents the $S N_{50}$ titer of serum from each group against specific strain.

The significance of dose-dependent variation of immune responses against multiple strains of each serotype have been analyzed also. One-way ANOVA test revealed highly significance $(p=<$ 0.001) of antibody raise among the immunized groups compared to that of non-vaccinated (placebo) negative control (NC). For all of the three FMDV serotype O viruses, there was no statistically significant difference between the positive control (PC) group and the full dose $(100 \mu \mathrm{g} / 1 \mathrm{ml}$ dose) immunization groups (Figure- 5A). Contrastingly, compared to the chimeric vaccine $(B 3)$, the PC group showed significantly $(\mathrm{p}<0.05)$ higher antibody level against the serotype A virus strains (BAN/CH/Sa-304/2016 and BAN/DH/Sa-310/2017) (Figure-5D). Importantly, the chimeric vaccine $(B 3)$ showed significantly $(p<0.001)$ higher antibody response than the PC group against FMDV strain BAN/GA/sa-197/2013, that previously reported to be mismatched with the developed inactivated vaccine formulated with BAN/CH/Sa-304/2016 [18, 20]. Variance of antibody level between other groups of vaccination doses has been illustrated in figure-5. 


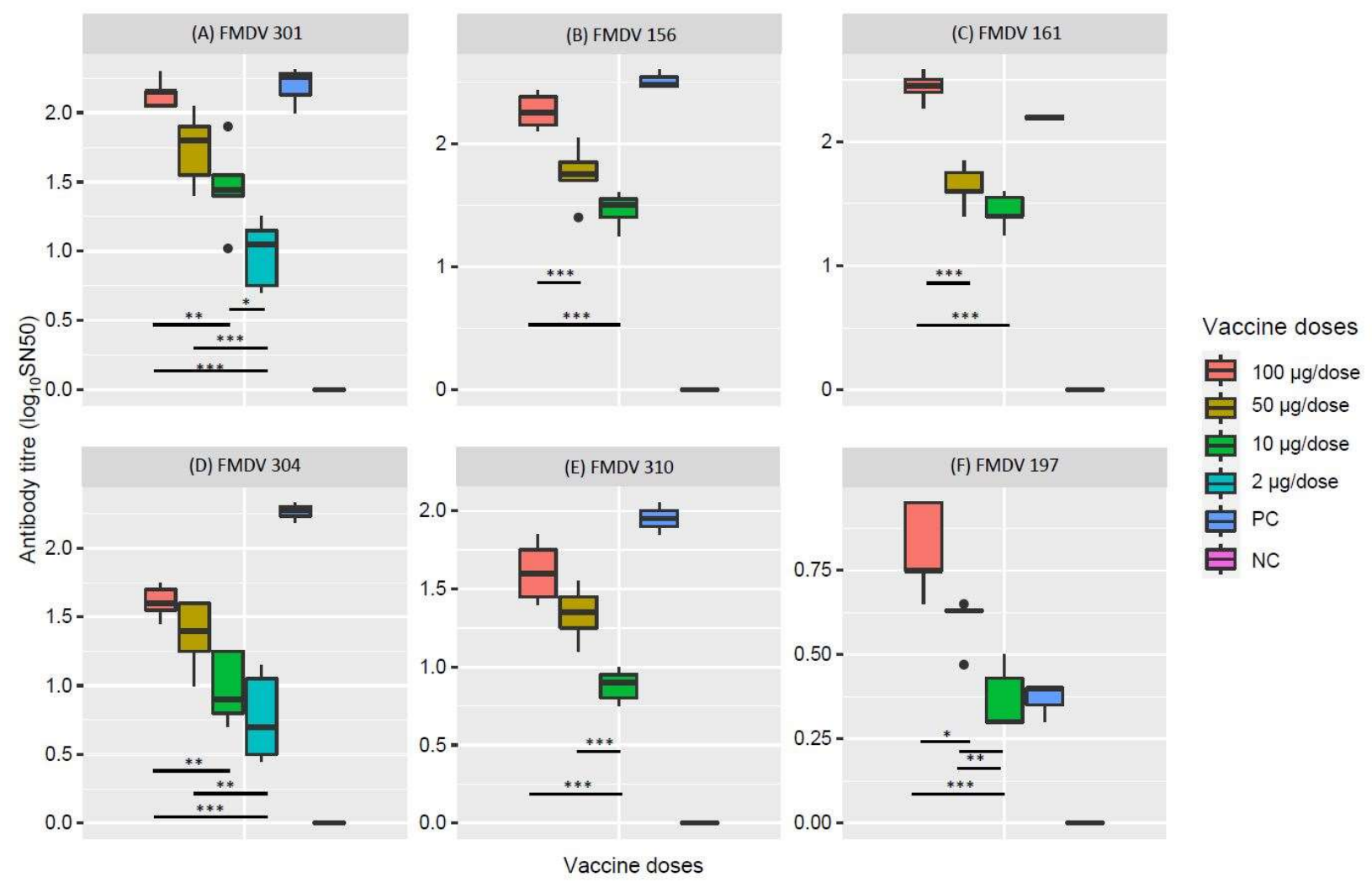

Fig. 5: Dose wise immune response variability of $B 1$ and B3 based vaccines against different field strains of FMDV. SN50 Titer of IgG in anti-B1 serum from different doses of B1 against serotypeO strains:(A) BAN/TA/Dh-301/2016, (B)BAN/NA/Ha-156/2013 and (C)BAN/BO/Na-161/2013. SN50 Titer of IgG in anti-B3 serum multiple doses of B3 against serotype-A strains: (D)BAN/CH/Sa-304/2016, (E)BAN/DH/Sa-310/2017 and (F)BAN/GA/Sa-197/2013. One-way ANOVA test revealed highly significance $(p=<0.001)$ of antibody raise between all the vaccinated groups compared and the non-vaccinated (placebo) negative control (NC) (not asterisked in the figure). Statistical significance between other doses has been asterisked at

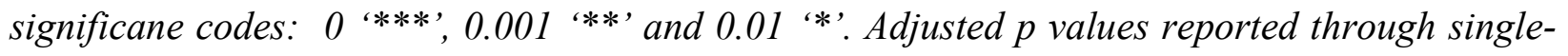
step method. $P C=$ positive control, $N C=$ negative control.

\section{Discussion}

\section{Multi-epitope Chimeric Proteins: New Savior for FMD Vaccination Strategy}

The development of subunit vaccine emerged as the most rational and cost-effective method for FMD vaccine [32]. The approach of multi-epitope based chimeric peptides is considered as the best strategy for preventing FMD for their capability of incorporating multiple epitope fragments 
in a single platform. A heterologous prokaryotic system for recombinant peptides expression has become prevalent and standardized due to the simple cultivation method, low maintenance cost and easy extraction protocols [56]. While using the prokaryotic system for eukaryotic peptides expression, one of the significant constraints is codon optimization and the solubility of the expressed peptides [57-59]. Also, the proper three-dimensional configurations of epitope fragments must permit the maximum exposure for effective antigen presentation and processing [60]. The artificial recombinant peptides must mimic the spatial arrangement of surface antigens to develop immune responses specific to target pathogens [61]. These factors have been emphasized in the novel design and orientations of both B1 and B3, respective vaccine candidates for FMDV type $\mathrm{O}$ and A circulating in Bangladesh.

\section{Rational Design, Orientation and Efficient Expression of Artificial Chimera B1 and B3}

Computational analysis of B1 and B3 constructs revealed that insertion of hydrophobic GG spacer sequence results formation of two recombinant peptides with much higher isoelectric points, 9.92 1nd 10.39, respectively. To increase the half-life and stability of tertiary conformation of the artificial peptides, we optimized the isoelectric point of both B1 and B3 by insertion of acidic amino acids in spacer sequences. Each GH-loop fragment of serotype-O strains contained a Cysteine residue complementing the probability of disulfide bridge in the final B1 chimeric peptides. So, GEDG is inserted in twelve spacer positions of B1. For lack of Cysteine in epitopes of serotype-A, GEDC spacer is inserted in four positions of B3 with GEDG spacer in eight positions.

The overexpressed peptides were abundant in insoluble fractions of total cell extract. The variation of IPTG concentration and cultivation temperature did not alter the solubility pattern of the overexpressed peptides (data not shown). The application of denaturing agent, 8M Urea, did not alter the physicochemical properties, molecular weight, and isoelectric point elucidated in SDSPAGE gel analysis. So, the orientation and combinations of epitope fragments of B1 and B3 were sustainable throughout the extraction and purification process. The optimized codons of mRNA, disulfide bridges, the higher number of hydrophilic amino acid residues in all twelve spacers sequence (GEDG) and nearly-neutral isoelectric point of B1 have rendered the cytoplasmic stability during heterologous expression and extracellular consistency throughout the purification process. The shortages of disulfide links between the GH loops and slightly higher isoelectric 
points have caused partial intracellular degradation of B3, which resulted in a lower yield of B3 than that of B1. Lower yield and cytoplasmic instability due to high $\mathrm{pI}$ has also been observed in the expression of another B1-like peptides (B2), with only change in the spacer region (GG). Notably, the isoelectric point of B2 was detected at 9.92 in silico. This peptide was also expressed but, after purification and SDS-PAGE detection, the peptides was found degraded into smaller fragments indicating cytoplasmic instability, proteolytic degradation and extracellular deterioration in the purification steps.

\section{Antigenic Stability and Protective Immunogenicity developed by B1 and B3}

The characterization and identification of purified B1 and B3 peptides through SDS-PAGE and Western Blot analysis revealed the validation of computationally predicted molecular weights and antigenic conformation. The arrangement of multiple epitopes in a single polypeptide must be designed to maintain the antigenicity similar to the infecting pathogen [62-64]. The distortion of antigenic configuration can result in misinterpretation of antigen presentation and the development of non-neutralizing antibodies. The serotype-specific anti-FMDV bovine serum-mediated WB detection of $\mathrm{B} 1$ and $\mathrm{B} 3$ indicates the presence of serologically active and accessible epitopes fragments on the surface of B1 and B3. The three-dimensional surface-orientation of RGD-motifs in GH-loops of the chimeric peptides have been revealed as capable of proper mimicking of FMDV surface epitopes essential for adaptive immune response. Although both of the chimeric peptides were purified from insoluble fractions under denaturing conditions, their tertiary configurations were renatured in PBS ( $\mathrm{pH}$ 7.4) solution which is evident in the subsequent characterization.

The virus neutralization tests revealed that all doses of antigens developed neutralizing antibodies in animal models. However, only higher concentrations, 100 and $50 \mu \mathrm{g} /$ doses of both antigens developed significant titer of neutralizing antibody at the protective level. Specifically, the in-vitro VN tests of both anti-B1 GP-sera of $100 \mu \mathrm{g}$ dose and monovalent anti-FMDV-O GP-sera showed the development of similar SN50 titer.

\section{Immune Response of B1 and B3 against Multiple Subgroups of FMDV serotype $O$ and $A$}

The artificially designed B1 antigen produces protective level of antibodies against the vaccine strain BAN/TA/Dh-301/2016, which belong to recently discovered Ind2001BD1 sub-lineage from Bangladesh. Besides, the $100 \mu \mathrm{g} /$ dose of B1 also produced protective level of antibody against BAN/NA/Ha-156/2013 and BAN/BO/Na-161/2013, which belong to Ind2001d lineage and 
recently reported Ind2001BD2 sub-lineage (Figure 4B,4C). Interestingly, the full dose of B1 antigen (100 $\mu \mathrm{g} /$ dose) and the full dose inactivated monovalent FMDV-O vaccine (BAN/TA/Dh/301-2016) produced similar level of protective response in animal models (Figure:5A,B,C). These results indicates that the multi-epitope B1 chimeric peptides possess immunogenic potency against the circulating lineages and recently emerged sub-lineage of serotype-O strains of FMDV. It can be clearly interpreted that full-dose B1 antigen can develop a protective immune response as efficient as a full-dose inactivated monovalent type-O vaccine against multiple lineage and sub-lineages of serotype-O. The incorporation of multiple epitopes from evolutionarily diverse subgroups of serotype $\mathrm{O}$ have been implemented the $\mathrm{B} 1$ construct design, which was not accomplished the previous works for peptide vaccine development against FMDV serotype-O.

Anti-B3 homologous GP sera from group E (immunized with $100 \mu \mathrm{g} / \mathrm{dose}$ ) showed that high doses of B3 antigen develop a protective antibody level, but lower than from an inactivated monovalent type-A vaccine. Despite the same antigen load, the lack of proper tertiary orientation and absence of disulfide bridges between epitope fragments have resulted in inefficient antigen processing and ultimately lower neutralizing efficiency of B3. The comparative serum neutralizing efficiency of both artificial B3 peptides and inactivated monovalent type-A FMDV vaccine demonstrated that $100 \mu \mathrm{g}$ of B3 antigen could not neutralize the infectious virus particles in-vitro as effectively as the full-dose inactivated vaccine. It is assumed that an increase of B3-antigen concentration shall overcome this limitation and enhance the neutralizing capacity of B3.

The neutralizing efficiency of anti-B3 sera indicated that the phylogenetically related strain BAN/DH/Sa-310/2017 was inhibited by anti-B3 sera in VN tests, except for BAN/GA/Sa197/2013 serotype-A strain. The amino acid changes within the BC loop of this strain rendered the serological insufficiency of both recombinant B3 antigen and inactivated vaccine, also reported by Al Amin et al.[18, 20]. Although, the GH-loop and C-terminal both B-cell epitopes of BAN/GA/Sa-197/2013 were incorporated in the B3 construct, sufficient antibodies were not developed to confer protection. It is noteworthy that the high dose of B3 antigen produced immune response at higher level than from the positive control (Figure-5F), which indicates the optimization of antigen load, inclusion of $\mathrm{BC}-$ loop and reconstruction of B3 can enhance 
expression and immunogenic stability to develop more potent vaccine candidate for FMDV serotype A in Bangladesh.

To enhance the cell-mediated immune responses, significant T-cell epitopes have been incorporated in both B1 and B3 constructs. These constructs are the very first design containing both universal and FMDV-originated T-cell epitopes in the single platforms along with B-cell epitopes. Although, the cytokine assays for quantitative detection of anti-viral immune responseindicators, like IFN- $\gamma$, IL-2, IL-4 could not be accomplished during this study due to poor availability of immunoassay kits for guinea pig cytokine assays during the COVID-19 pandemic. Several reports showed that the inclusion of $\mathrm{CpG}$ oligonucleotide enhances the immunogenicity of recombinant peptides-based vaccine candidates [65]. These modifications can be explored to enhance the efficacy of the B1 and B3 antigens in future studies.

\section{Conclusion}

To control and restrict the transboundary transmission and prevalence of FMD, caused by type-O strains closely related to Ind2001BD1 sub-lineage in Bangladesh and neighboring territories, the application of multiple epitopes based recombinant vaccines will enhance immune diversity targeting most prevalent genotypes. This study presents the novel designs for FMDV vaccine candidates comprised of protective antigens from the most recent sub-lineage, highly capable of transboundary transmission. The sero-protection efficiencies of the recombinant peptides should be further assessed through live virus challenge tests in guinea pig and cattle models, along with homologous and heterologous virus strains isolated from different FMD endemic in this south Asian region.

\section{Supplementary Materials:}

- Supplementary Table 1: FMDV Serotype O isolates used in Phylogenetic analysis;

- Supplementary Table 2: FMDV Serotype A isolates used in Phylogenetic analysis;

- Supplementary Table-3: Immunization Plan of Experimental guinea pigs;

- Supplementary Table-4: Physicochemical parameters of B1 and B3;

- Suppl. Figure 1: Wu-Kabat peptides variability plot for VP1 type O and A circulating in Bangladesh. Variability was most observed at G-H loop [135-158] and C-termini [195211] positions. (a) Variability plot of the whole VP1 peptides of serotype O, (b) Variability plot of the whole VP1 peptides of serotype A;

- Suppl. Figure-2: Map of pET 21a $(+)$ expression vector with selectable marker.

- Suppl. Figure-3: Insertion sequences and amino acid sequences of B1 and B3. 
- Suppl. Figure-4: Ethical Clearance for the experiment (Ref:66/Biol.Scs./2018-19; Date: 14-11-2018)

\section{Author Contributions:}

Conceptualization, SALMA AKTER; Data curation, SALMA AKTER, Md. Shaminur Rahman, Masuda Akther and Mafruha Marjia; Formal analysis, Md. Shaminur Rahman and M. Rafiul Islam; Funding acquisition, Munawar Sultana and M. Anwar Hossain; Investigation, SALMA AKTER, Masuda Akther and Mafruha Marjia; Methodology, SALMA AKTER, Md. Shaminur Rahman, M. Rafiul Islam, Masuda Akther and Mafruha Marjia; Project administration, Munawar Sultana and M. Anwar Hossain; Resources, Munawar Sultana and M. Anwar Hossain; Software, SALMA AKTER, Md. Shaminur Rahman and M. Rafiul Islam; Supervision, Munawar Sultana and M. Anwar Hossain; Validation, SALMA AKTER and Masuda Akther; Visualization, Md. Shaminur Rahman and M. Rafiul Islam; Writing - original draft, SALMA AKTER; Writing review \& editing, Md. Shaminur Rahman, M. Rafiul Islam, Md. Mizanur Rahman, Munawar Sultana and M. Anwar Hossain.

\section{Funding:}

This research work was carried out jointly from funding allocation by the University Grants Commission (UGC), Government of the People's Republic of Bangladesh and another grant from UNESCO and the International Development Research Centre, Ottawa, Canada. The UGC-fund was provided to Professor M. Anwar Hossain, Department of Microbiology, University of Dhaka through the Higher Education Quality Enhancement Project (HEQEP) grant number CP-3842. Significant part of this work was carried out with the aid from UNESCO provided to Dr. Munawar Sultana, Department of Microbiology, University of Dhaka. Notably, the views expressed herein do not necessarily represent those of UNESCO, IDRC or its Board of Governors.

\section{Institutional Review Board Statement:}

The study was conducted according to the guidelines of the Ethical Review Committee of the Faculty of Biological Sciences, University of Dhaka. The reference number is “Ref:66/Biol.Scs./2018-2019" approved on 14-11-2018 (Supplementary Figure- 4).

\section{Conflicts of Interest:}

The authors declare no conflict of interest. The funding authorities had no role in the design of the study; methodology development; in the collection, analyses, or interpretation of data; in the writing of the manuscript, or in the decision to publish the results.

\section{References:}

1. Rodriguez, L. L.; Gay, C. G., Development of vaccines toward the global control and eradication of foot-and-mouth disease. Expert review of vaccines 2011, 10, (3), 377-387. 
2. Brito, B.; Pauszek, S. J.; Eschbaumer, M.; Stenfeldt, C.; de Carvalho Ferreira, H. C.; Vu, L. T.; Phuong, N. T.; Hoang, B. H.; Tho, N. D.; Dong, P. V., Phylodynamics of foot-and-mouth disease virus O/PanAsia in Vietnam 2010-2014. Veterinary research 2017, 48, (1), 24.

3. Thompson, D.; Muriel, P.; Russell, D.; Osborne, P.; Bromley, A.; Rowland, M.; Creigh-Tyte, S.; Brown, C., Economic costs of the foot and mouth disease outbreak in the United Kingdom in 2001. Revue scientifique et technique (International Office of Epizootics) 2002, 21, (3), 675-687.

4. Cottam, E. M.; Haydon, D. T.; Paton, D. J.; Gloster, J.; Wilesmith, J. W.; Ferris, N. P.; Hutchings, G. H.; King, D. P., Molecular epidemiology of the foot-and-mouth disease virus outbreak in the United Kingdom in 2001. Journal of Virology 2006, 80, (22), 11274-11282.

5. Muroga, N.; Hayama, Y.; Yamamoto, T.; Kurogi, A.; Tsuda, T.; Tsutsui, T., The 2010 foot-andmouth disease epidemic in Japan. Journal of Veterinary Medical Science 2012, 74, (4), 399-404.

6. Fukai, K.; Nishi, T.; Shimada, N.; Morioka, K.; Yamada, M.; Yoshida, K.; Sakamoto, K.; Kitano, R.; Yamazoe, R.; Yamakawa, M., Experimental infections using the foot-and-mouth disease virus O/JPN/2010 in animals administered a vaccine preserved for emergency use in Japan. Journal of Veterinary Medical Science 2016, 16-0482.

7. Nishi, T.; Yamada, M.; Fukai, K.; Shimada, N.; Morioka, K.; Yoshida, K.; Sakamoto, K.; Kanno, T.; Yamakawa, M., Genome variability of foot-and-mouth disease virus during the short period of the 2010 epidemic in Japan. Veterinary microbiology 2017, 199, 62-67.

8. Zheng, H.; He, J.; Guo, J.; Jin, Y.; Yang, F.; Lv, L.; Liu, X., Genetic characterization of a new pandemic Southeast Asia topotype strain of serotype $O$ foot-and-mouth disease virus isolated in China during 2010. Virus Genes 2012, 44, (1), 80-88.

9. Park, J.-N.; Lee, S.-Y.; Chu, J.-Q.; Lee, Y.-J.; Kim, R.-H.; Lee, K.-N.; Kim, S.-M.; Tark, D.-S.; Kim, B.; Park, J.-H., Protection to homologous and heterologous challenge in pigs immunized with vaccine against foot-and-mouth disease type $O$ caused an epidemic in East Asia during 2010/2011. Vaccine 2014, 32, (16), 1882-1889.

10. Sobrino, F.; Domingo, E., Foot-and-mouth disease in Europe. EMBO reports 2001, 2, (6), 459461.

11. Paton, D. J.; Di Nardo, A.; Knowles, N. J.; Wadsworth, J.; Pituco, E. M.; Cosivi, O.; Rivera, A. M.; Kassimi, L. B.; Brocchi, E.; de Clercq, K., The history of foot-and-mouth disease virus serotype C: the first known extinct serotype? Virus Evolution 2021, 7, (1), veab009.

12. Jamal, S. M.; Belsham, G. J., Molecular epidemiology, evolution and phylogeny of foot-andmouth disease virus. Infection, Genetics and Evolution 2018, 59, 84-98.

13. Momtaz, S.; Rahman, A.; Sultana, M.; Hossain, M. A., Evolutionary analysis and prediction of peptide vaccine candidates for foot-and-mouth-disease virus types $A$ and $O$ in Bangladesh. Evolutionary Bioinformatics 2014, 10, EBO. S17027.

14. Mateu, M. G.; Camarero, J. A.; Giralt, E.; Andreu, D.; Domingo, E., Direct evaluation of the immunodominance of a major antigenic site of foot-and-mouth disease virus in a natural host. Virology 1995, 206, (1), 298-306.

15. Carrillo, C.; Tulman, E.; Delhon, G.; Lu, Z.; Carreno, A.; Vagnozzi, A.; Kutish, G.; Rock, D., Comparative genomics of foot-and-mouth disease virus. Journal of virology 2005, 79, (10), 64876504.

16. Fernandez-Sainz, I.; Gavitt, T. D.; Koster, M.; Ramirez-Medina, E.; Rodriguez, Y. Y.; Wu, P.; Silbart, L. K.; de Los Santos, T.; Szczepanek, S. M., The VP1 GH loop hypervariable epitope contributes to protective immunity against Foot and Mouth Disease Virus in swine. Vaccine 2019, 37, (26), 3435-3442.

17. Marrero, R.; Limardo, R. R.; Carrillo, E.; König, G. A.; Turjanski, A. G., A computational study of the interaction of the foot and mouth disease virus VP1 with monoclonal antibodies. Journal of immunological methods 2015, 425, 51-57. 
18. Islam, M. R.; Rahman, M. S.; Amin, M. A.; Alam, A. R. U.; Siddique, M. A.; Sultana, M.; Hossain, M. A., Evidence of combined effect of amino acid substitutions within G-H and B-C loops of VP1 conferring serological heterogeneity in foot-and-mouth disease virus serotype A. Transboundary and Emerging Diseases 2021, 68, (2), 375-384.

19. Parida, S., Vaccination against foot-and-mouth disease virus: strategies and effectiveness. Expert review of vaccines 2009, 8, (3), 347-365.

20. Al Amin, M.; Ali, M. R.; Islam, M. R.; Alam, A. R. U.; Shill, D. K.; Rahman, M. S.; Siddique, M. A.; Sultana, M.; Hossain, M. A., Development and serology based efficacy assessment of a trivalent foot-and-mouth disease vaccine. Vaccine 2020.

21. Al Amin, M.; Ali, M. R.; Alam, A. R. U.; Siddique, M. A.; Rahaman, M. M.; Sultana, M.; Hossain, M. A., Complete genome sequence of a potential foot-and-mouth disease virus serotype $O$ vaccine strain from Bangladesh. Archives of Virology 2020, 165, (9), 2119-2122.

22. Ali, M. R.; Alam, A. R. U.; Amin, M. A.; Siddique, M. A.; Sultana, M.; Hossain, M. A., Emergence of novel lineage of foot-and-mouth disease virus serotype Asia1 BD-18 (G-IX) in Bangladesh. Transboundary and emerging diseases 2020, 67, (2), 486-493.

23. Amin, M. A.; Ali, M. R.; Alam, A. S. M. R. U.; Siddique, M. A.; Ullah, H.; Sultana, M.; Hossain, M. A., Near-Complete Genome Sequence of a Potential Foot-and-Mouth Disease Virus Serotype A Vaccine Strain Isolated from Bangladesh. Microbiology Resource Announcements 2019, 8, (37), e00031-19.

24. Cottam, E. M.; Wadsworth, J.; Shaw, A. E.; Rowlands, R. J.; Goatley, L.; Maan, S.; Maan, N. S.; Mertens, P. P.; Ebert, K.; Li, Y., Transmission pathways of foot-and-mouth disease virus in the United Kingdom in 2007. PLoS pathogens 2008, 4, (4), e1000050.

25. Paton, D.; Reeve, R.; Capozzo, A. V.; Ludi, A., Estimating the protection afforded by foot-andmouth disease vaccines in the laboratory. Vaccine 2019, 37, (37), 5515-5524.

26. Ullah, H.; Siddique, M.; Al Amin, M.; Das, B.; Sultana, M.; Hossain, M., Re-emergence of circulatory foot-and-mouth disease virus serotypes Asia1 in Bangladesh and VP1 protein heterogeneity with vaccine strain IND 63/72. Letters in applied microbiology 2015, 60, (2), 168173.

27. Siddique, M.; Ali, M.; Alam, A.; Ullah, H.; Rahman, A.; Chakrabarty, R.; Amin, M.; Hoque, S.; Nandi, S.; Sultana, M., Emergence of two novel sublineages Ind2001 BD 1 and Ind2001 BD 2 of foot-and-mouth disease virus serotype $O$ in Bangladesh. Transboundary and emerging diseases 2018, 65, (4), 1009-1023.

28. Zhu, Z.; Yang, F.; He, J.; Li, J.; Cao, W.; Li, J.; Xia, Y.; Guo, J.; Jin, Y.; Zhang, K., First detection of foot-and-mouth disease virus O/ME-SA/Ind2001 in China. Transboundary and emerging diseases 2018, 65, (6), 2027-2031.

29. Hemida, M. G.; Rizk EL-Ghareeb, W.; Al-Hizab, F.; Ibrahim, A., Foot-and-mouth disease virus $\mathrm{O} / \mathrm{ME}-\mathrm{SA} /$ Ind 2001 lineage outbreak in vaccinated Holstein Friesian cattle in Saudi Arabia in 2016. Veterinary Quarterly 2018, 38, (1), 88-98.

30. Rudreshappa, A. G.; Sanyal, A.; Mohapatra, J. K.; Subramaniam, S.; De, A.; Das, B.; Singanallur, N. B.; Jangam, A. K.; Muthukrishnan, M.; Villuppanoor, S. A., Emergence of antigenic variants with in serotype $A$ foot and mouth disease virus in India and evaluation of a new vaccine candidate panel. Veterinary microbiology 2012, 158, (3-4), 405-409.

31. Mahapatra, M.; Parida, S., Foot and mouth disease vaccine strain selection: current approaches and future perspectives. Expert review of vaccines 2018, 17, (7), 577-591.

32. Rodriguez, L. L.; Grubman, M. J., Foot and mouth disease virus vaccines. Vaccine 2009, 27, D90D94. 
33. Lee, H.-B.; Piao, D.-C.; Lee, J.-Y.; Choi, J.-Y.; Bok, J.-D.; Cho, C.-S.; Kang, S.-K.; Choi, Y.-J., Artificially designed recombinant protein composed of multiple epitopes of foot-and-mouth disease virus as a vaccine candidate. Microbial cell factories 2017, 16, (1), 33.

34. Bittle, J. L.; Houghten, R. A.; Alexander, H.; Shinnick, T. M.; Sutcliffe, J. G.; Lerner, R. A.; Rowlands, D. J.; Brown, F., Protection against foot-and-mouth disease by immunization with a chemically synthesized peptide predicted from the viral nucleotide sequence. Nature 1982, 298, (5869), 30.

35. DiMarchi, R.; Brooke, G.; Gale, C.; Cracknell, V.; Doel, T.; Mowat, N., Protection of cattle against foot-and-mouth disease by a synthetic peptide. Science 1986, 232, (4750), 639-641.

36. Wang, C. Y.; Chang, T. Y.; Walfield, A. M.; Ye, J.; Shen, M.; Chen, S. P.; Li, M. C.; Lin, Y. L.; Jong, M. H.; Yang, P. C., Effective synthetic peptide vaccine for foot-and-mouth disease in swine. Vaccine 2002, 20, (19-20), 2603-2610.

37. Cubillos, C.; Beatriz, G.; Jakab, A.; Clementi, G.; Borrás, E.; Bárcena, J.; Andreu, D.; Sobrino, F.; Blanco, E., Enhanced mucosal immunoglobulin A response and solid protection against foot-andmouth disease virus challenge induced by a novel dendrimeric peptide. Journal of virology 2008, 82, (14), 7223-7230.

38. Shao, J.-J.; Wong, C. K.; Lin, T.; Lee, S. K.; Cong, G.-Z.; Sin, F. W. Y.; Du, J.-Z.; Gao, S.-D.; Liu, X.-T.; Cai, X.-P., Promising multiple-epitope recombinant vaccine against foot-and-mouth disease virus type $O$ in swine. Clin. Vaccine Immunol. 2011, 18, (1), 143-149.

39. Agadjanyan, M. G.; Ghochikyan, A.; Petrushina, I.; Vasilevko, V.; Movsesyan, N.; Mkrtichyan, M.; Saing, T.; Cribbs, D. H., Prototype Alzheimer's disease vaccine using the immunodominant B cell epitope from $\beta$-amyloid and promiscuous T cell epitope pan HLA DR-binding peptide. The Journal of Immunology 2005, 174, (3), 1580-1586.

40. Alexander, J.; del Guercio, M.-F.; Maewal, A.; Qiao, L.; Fikes, J.; Chesnut, R. W.; Paulson, J.; Bundle, D. R.; DeFrees, S.; Sette, A., Linear PADRE T helper epitope and carbohydrate B cell epitope conjugates induce specific high titer IgG antibody responses. The Journal of Immunology 2000, 164, (3), 1625-1633.

41. Benson, D. A.; Cavanaugh, M.; Clark, K.; Karsch-Mizrachi, I.; Lipman, D. J.; Ostell, J.; Sayers, E. W., GenBank. Nucleic acids research 2012, 41, (D1), D36-D42.

42. Zuker, M., Mfold web server for nucleic acid folding and hybridization prediction. Nucleic acids research 2003, 31, (13), 3406-3415.

43. Sato, K.; Hamada, M.; Asai, K.; Mituyama, T., CENTROIDFOLD: a web server for RNA secondary structure prediction. Nucleic acids research 2009, 37, (suppl_2), W277-W280.

44. Sen, T. Z.; Jernigan, R. L.; Garnier, J.; Kloczkowski, A., GOR V server for protein secondary structure prediction. Bioinformatics 2005, 21, (11), 2787-2788.

45. Cole, C.; Barber, J. D.; Barton, G. J., The Jpred 3 secondary structure prediction server. Nucleic acids research 2008, 36, (suppl_2), W197-W201.

46. Rost, B.; Liu, J., The predictprotein server. Nucleic acids research 2003, 31, (13), 3300-3304.

47. Lee, W.; Stark, J. L.; Markley, J. L., PONDEROSA-C/S: client-server based software package for automated protein 3D structure determination. Journal of biomolecular NMR 2014, 60, (2-3), 73-75.

48. Lee, W.; Cornilescu, G.; Dashti, H.; Eghbalnia, H. R.; Tonelli, M.; Westler, W. M.; Butcher, S. E.; Henzler-Wildman, K. A.; Markley, J. L., Integrative NMR for biomolecular research. Journal of biomolecular NMR 2016, 64, (4), 307-332.

49. Laskowski, R. A.; MacArthur, M. W.; Moss, D. S.; Thornton, J. M., PROCHECK: a program to check the stereochemical quality of protein structures. Journal of applied crystallography 1993, 26, (2), 283-291. 
50. Gasteiger, E.; Hoogland, C.; Gattiker, A.; Wilkins, M. R.; Appel, R. D.; Bairoch, A., Protein identification and analysis tools on the ExPASy server. The proteomics protocols handbook 2005, 571-607.

51. Kärber, G., Beitrag zur kollektiven Behandlung pharmakologischer Reihenversuche. NaunynSchmiedebergs Archiv für experimentelle pathologie und pharmakologie 1931, 162, (4), 480-483.

52. Daoud, H. M.; Ibrahim, E. E.-S.; El-Din, W. M. G.; Hassanin, A. I. H., Preparation of Foot and Mouth Disease trivalent vaccine type A, O, SAT2 with determination of the Guinea pig protective dose 50 (GPPD50). Veterinary World 2013, 6, (11), 844.

53. Motamedi Sedeh, F.; Khorasani, A.; Shafaee, K.; Salehizadeh, M.; Fatolahi, H.; Arbabi, K.; Daneshvari, S.; Abhari, M., Immune response of foot and mouth disease virus type A87/IRN inactivated vaccine by gamma irradiation on guinea pig in Iran. Iranian Journal of Science and Technology (Sciences) 2007, 31, (1), 35-41.

54. Team, R. C., R: A language and environment for statistical computing. 2013.

55. Wickham, H., ggplot2. Wiley Interdisciplinary Reviews: Computational Statistics 2011, 3, (2), 180185.

56. Stevens, R. C., Design of high-throughput methods of protein production for structural biology. Structure 2000, 8, (9), R177-R185.

57. Al-Hawash, A. B.; Zhang, X.; Ma, F., Strategies of codon optimization for high-level heterologous protein expression in microbial expression systems. Gene Reports 2017, 9, 46-53.

58. Mignon, C.; Mariano, N.; Stadthagen, G.; Lugari, A.; Lagoutte, P.; Donnat, S.; Chenavas, S.; Perot, C.; Sodoyer, R.; Werle, B., Codon harmonization-going beyond the speed limit for protein expression. FEBS letters 2018, 592, (9), 1554-1564.

59. Gustafsson, C.; Govindarajan, S.; Minshull, J., Codon bias and heterologous protein expression. Trends in biotechnology 2004, 22, (7), 346-353.

60. Roseman, A.; Borschukova, O.; Berriman, J.; Wynne, S.; Pumpens, P.; Crowther, R., Structures of hepatitis $B$ virus cores presenting a model epitope and their complexes with antibodies. Journal of molecular biology 2012, 423, (1), 63-78.

61. Soria-Guerra, R. E.; Nieto-Gomez, R.; Govea-Alonso, D. O.; Rosales-Mendoza, S., An overview of bioinformatics tools for epitope prediction: implications on vaccine development. Journal of biomedical informatics 2015, 53, 405-414.

62. Hajighahramani, N.; Nezafat, N.; Eslami, M.; Negahdaripour, M.; Rahmatabadi, S. S.; Ghasemi, Y., Immunoinformatics analysis and in silico designing of a novel multi-epitope peptide vaccine against Staphylococcus aureus. Infection, Genetics and Evolution 2017, 48, 83-94.

63. López-Sagaseta, J.; Malito, E.; Rappuoli, R.; Bottomley, M. J., Self-assembling protein nanoparticles in the design of vaccines. Computational and structural biotechnology journal 2016, 14, 58-68.

64. Wang, Y.; Wang, M.; Wang, G.; Pang, A.; Fu, B.; Yin, H.; Zhang, D., Increased survival time in mice vaccinated with a branched lysine multiple antigenic peptide containing B-and T-cell epitopes from T. gondii antigens. Vaccine 2011, 29, (47), 8619-8623.

65. Cao, Y.; Li, D.; Fu, Y.; Bai, Q.; Chen, Y.; Bai, X.; Jing, Z.; Sun, P.; Bao, H.; Li, P., Rational design and efficacy of a multi-epitope recombinant protein vaccine against foot-and-mouth disease virus serotype A in pigs. Antiviral research 2017, 140, 133-141. 